\title{
Glass Ceiling and Women Career Development in Nepalese Commercial Banks
}

\author{
Indira Shrestha \\ Lecturer, Nepal Commerce Campus, T.U.
}

\begin{abstract}
The purpose of this study is to examine the impact of the glass ceiling $(G C)$ on women's career development (WCD) in Nepalese commercial banks. One hundred and forty-four women branch managers working in different branches were taken as the sample. The study used a survey questionnaire (17 items) derived from women workplace culture questionnaire (WWC) (Bergman and Hallberg, 2002) for measuring glass ceiling, used as an independent variable in the study. Additionally, a career satisfaction questionnaire developed by (Greenhaus, Parasuraman, and Wormley1990) was used to measure WCD (dependent variable).The statistical tools like Pearson correlation and regression analysis were applied to find the result of quantitative data. The result revealed that there is an existence of GC in commercial banks in Nepal and the negative relationship between $G C$ and the WCD along with the impact of the corporate climate on the WCD. Some limitations of the study have been found and implications and recommendation for the future researchers are also discussed.
\end{abstract}

Keywords: Glass ceiling, Career development, Banks, Corporate culture

\section{Introduction}

Women and gender issues in employment regarding career development in the business arena have been a major concern. Alvesson and Billing (2010) have said that women's employment has got more attention from the perspective of career advancement. This is natural because an increasing number of women are in the workforce, but only a very small percentage holds the top-level positions in business and public administration. Some of the studies mention that during the last two decades, there has been an increase in the proportion of women at entry and the middle-level management positions, resulting mostly from the activities of the women's movement, polices of the political system and corporate equal opportunity initiatives. Meyerson and Fletcher (2000) say that women at the top-level of business still seem rare. They comprise only 10 percent of senior managers in Fortune 500 companies, less than 4 percent of the highest ranks of CEO.

Catalyst (2018) shows that women currently hold 5 percent of CEO positions, 21.2 percent of board seats, 26.5 percent of executive/senior-level officials, and 36.9 percent of the first/middle-level officials and managers. This shows women at the lower level to the top-level management are still rare.

In the Nepali context, not much effort has been done in exploring the career progression for Nepali women employees although Nepali women in the formal employment sector are increasing (Central Bureau of Statistics [CBS], 2009). 


\section{Statement of the Problems}

In 25 commercial banks owned by the general public, out of 25 chief executive officers (CEOs), only one CEO is a woman and became the first woman CEO of one of the commercial banks in Nepal. Similarly, out of 2147 branch managers, males are 1922 (89.52 percent) and females are 225 (10.48 percent), (Source: websites of 25 commercial banks, 2018). It shows that even in lower-level management, women representation is less. So some issues can be raised, like gender issues or the existence of GC in WCD in commercial banks. The outcomes of the research studies regarding GC and WCD are not consistent so the study on this area in the context of Nepalese commercial banks is assumed noteworthy. The major issues of women branch managers of commercial banks regarding GC and WCD have been traced as given below:

i. Is there any relationship between the glass ceiling and the career development of women branch managers in commercial banks?

ii. Is there any impact of glass ceiling variables (corporate culture, corporate climate, and corporate practice) on the career development of women branch managers in commercial banks?

\section{Objectives of the Study}

The general objective of this study is to examine the impact of GC on CD among women branch managers of Nepalese commercial banks and the specific objectives of the study are as follows:

i. To analyze the relationship between the glass ceiling and the career development of women branch managers incommercial banks.

ii. To examine the impact of glass ceiling variables (corporate culture, corporate climate, and corporate practice) on the career development of women branch managers in commercial banks.

\section{Literature Review}

\section{Glass ceiling}

The 'glass ceiling' is reflected in corporate culture, corporate practices, and corporate climate. The term 'glass ceiling' is used to describe all the frustrations of working women at every level who can see where they want to get to but who find themselves blocked by an invisible barrier (Mavin, 2000).

\section{Glass ceiling and corporate culture}

Stereotype refers to a discrepancy between the management role and gender role of women achieving a career in management. When women show the predominant male management style, they are criticized for being too aggressive and bossy, and when they use a feminine management style, they are considered ineffective leaders (Cooper, 2001; Ragins et al., 1998).

\section{Glass ceiling and corporate climate}

According to Jackson, (2001) organizational climate is normally used in the literature to refer to prevailing corporate perceptions of women's professional capabilities and commitment to their careers.

\section{Glass ceiling and corporate practice}

Knuston and Schmidgall, (1999) say corporate practices may include training and development, networking and mentoring, flexible working hours, and other family-friendly initiatives. Buttigieg and Walsh (2000) their study showed that to achieve promotion, women had to conform more stringent, and performance-based criteria than did their male counterparts.

\section{Glass ceiling and women career development}

The GC theory is not supported in the context of Lebanese banks with overall positive inferences and 
perceptions reported by Lebanese women managers to their work environment and daily work experiences. (Jamali, Safieddine, and Daouk, 2006). Dimovski, Skerlavaj and Mok Kim Man (2010) their findings showed that women middle managers in Singapore organizations faced a GC in their working environment which, preventsthem from ascending to a higher position. Bombuwela, Alwis, and Chamaru (2013) found that GC and WCD have a moderate negative relationship and organizational factors, individual factors except family factors have a significant effect on WCD. Neseer, Shabbir, and Batool (2017) found that $62.7 \%$ of women who are doing jobs in the public sector of Punjab province have faced the Glass ceiling. $70 \%$ of the respondents have said that beyond a certain point, women cannot grow in the organization.

\section{Career development}

Career success is the positive psychological or work-related outcomes or achievements onehas accumulated as a result of one's work experiences (Judge et al. 1995). Career satisfactionrefers to satisfaction, individuals derive from intrinsic and extrinsic aspects of their career, includingpay, advancement, and developmental opportunities (Greenhaus, et al.,1990).

\section{Existence of glass ceiling}

Thao (2014) found that half of the respondents have felt the existence of GCto a moderate extent and $16.2 \%$ percentage of participants felt the existence of the GC to a great extent.Very few respondents acknowledge the existence of the GC to a very great extent or no extent at all.

\section{Research gap}

Most of the work related to GC has been conducted in a different part of the world but very less in Nepal and their results might not be generalized within the corporate world among different countries. There exists a potential gap in adopting the results of this researches on the GC and WCD in the context of Nepal.So to fulfill this research gap, the researcher has tried to analyze the impact of GC on the WCD in the context of the Nepalese commercial bank.

\section{Conceptual framework}

Based on the arguments above and literature review, the conceptual framework on the issues has been drawn accordingly in the Nepalese context as well. This study has conceptualized that GC has an impact on WCD.

Independent variable Dependent variable Glass Ceiling

\begin{tabular}{|l|l|l|}
\hline $\begin{array}{l}\text { i) Corporate culture } \\
\text { ii) Corporate climate } \\
\text { iii) Corporate practice }\end{array}$ & Women Career Development \\
& & \\
\hline
\end{tabular}

Figure 2.1 Schematic diagram of conceptual framework

\section{Hypotheses formulation}

H1: There is a significant relationship between $\mathrm{GC}$ and $\mathrm{CD}$ among women branch managers of commercial banks.

$\mathrm{H} 2$ : There is a significant impact of GC variables (corporate culture, corporate climate, and corporate practice), on career development among women branch managers of commercial banks. 


\section{Research Methods}

For this study, descriptive and causal-comparative research designs have been employed to analyze the impact of the glass ceiling (independent variable) on WCD (dependent variable) among women branch managers of commercial banks.

Population-The Population for this study is women branch managers from twenty-five commercial banks. The total population is 225 and has been identified by the researcher through websites of twenty-five commercial banks.

Sample size- To determine the sample size, the following formula has been used.

$\mathrm{n}=\mathrm{N} / 1+\mathrm{N}\left(\mathrm{e}^{2}\right)$

$\mathrm{n}=225 / 1+225\left(0.05^{2}\right)$

$\mathrm{n}=225 / 1.5625$

$\mathrm{n}=144$.

Where,

$\mathrm{n}=$ sample size, $\mathrm{N}=$ population, $\mathrm{e}=$ margin of error $(5 \%)$

Based on the calculation of sample size determination formula, the sample for this study comprised 144 women respondents employing as branch managers.

Nature and sources of data and sampling procedure- This study is based on primary data. Structure questionnaires had been distributed to elicit the opinions of the respondents. The Self-administered online survey questionnaire was proposed for the respondents who work as a branch manager in branches of commercial banks situated out of Kathmandu and Pokhara valley. The name of women managers, contact number and email ID were identified through websites of 25 commercial banks. 38 out of 144 respondents filled out the online survey questionnaire and most of them were from out of Kathmandu and Pokhara valley. Rest of them filled out the survey questionnaire face-to-face in the presence of the researcher who visited them during normal working hour and some of them preferred to fill out and return the questionnaires at their convenience. This method was applied to respondents of Kathmandu valley and Pokhara valley. A simple random sampling method has been used to help minimize sampling errors or biases making a representative sample.

\section{Independent variables}

The measurement of the glass ceiling as an independent variable is based on "corporate culture", "corporate practice" and "corporate climate".

\section{Corporate culture}

According to Robbins and Coulter, (2003) corporate culture is the values, beliefs, and norms shared by organizational members that govern how they behave towards each other and outsiders. Corporate culture consists of 5 items and most of them adapted from (WWC) (Bergman and Hallberg, 2002) and remaining from other literature.

\section{Corporate practice}

Ragins,et al. (1998) found that 94 percent of the respondents said that handling difficult or highly visible assignments is important to their success as well as they need to seek out these assignments more than their male counterparts. The Corporate practice consists of 5 items and adapted from (WWC) (Bergman and Hallberg, 2002). The agreement factors for corporate practice are like "Women have fewer opportunities than men for professional development at work"

\section{Corporate climate}

Women are reported in the literature to be often subject to negative attitudes and stereotypes at $\sim 62 \sim$ 
work questioning their participation, contribution, commitment, and capabilities (Jackson, 2001; Mott, 1998cited in Jamali, et al., 2006). The Corporate climate consists of 7 items and adapted from (WWC) (Bergman and Hallberg, 2002). The agreement factors for corporate climate are like "negative perceptions and stereotypes about women's professional capabilities constitute barriers to women's advancement", and "Women are perceived to be less committed at the workplace".

\section{Dependent variable:}

Women career development- Career success is the positive psychological or work-related outcomes or achievements onehas accumulated as a result of one's work experiences (Judge et al. 1995). So to understand, whether women branch managers are satisfied with career development opportunities available to them by the organization, the researcher has adapted from the career satisfaction questionnaire developed by (Greenhaus, et al., 1990). The items are like (i) I am satisfied withthe success I have achieved in my career, (ii) I am satisfied with the progress I have made toward meeting mygoals for the development of new skills.

\section{Supportive information}

As supportive information for the glass ceiling, the researcher asked one additional question like the existence of a glass ceiling in an organization adapted from (Thao, 2014).

\section{Measurement of variables}

WCD and GC questionnaire have been measured on a Likert's 5 points scale ranging from Strongly Agree (5), to Strongly Disagree (1). One additional question under supportive information has been measured on a 5 points ranging from "to extent" (1), "to a little extent" (2), "to a moderate extent" (3), "to a great extent (4), to "to a very great extent" (5).

Reliability-For internal consistency of variables, reliability test (Cronbach $\alpha$ ) has been calculated for WCD and GC questionnaire.

For the internal consistency reliability test of the WCD and GCquestionnaire, the Cronbach $\alpha$ coefficient was calculated. Cronbach $\alpha$ coefficient for GC (items 17) was 0.947. Cronbach $\alpha$ coefficient of WCD (5 items) revealed 0.890.Cronbach alpha coefficient for scales are CC -5 items $(\alpha=0.890)$, CCL- 7 items $(\alpha=0.872)$, CP- 5 items $(\alpha=0.885)$. As indicated, the Cronbach alpha coefficients for all multi-item scales exceed the 0.70 level as recommended by Nunnally and Bernstein (1994).

Validity- GC questions have been adapted from (WWC) (Bergman and Hallberg, 2002) and women's career development questions have been adapted from career satisfaction(Greenhaus, et al.,1990). Furthermore, to contextualize in the questionnaire, expert opinion and some female employees' opinion of commercial banks have been solicited and the researcher has simplified questionnaire accordingly.

Collinearity test- The variance inflation factor (VIF) of three variables under GC showed with CC $(\mathrm{VIF}=2.657), \mathrm{CCL}(\mathrm{VIF}=3.279), \mathrm{CP}(\mathrm{VIF}=3.404)$. All VIF values are less than 10 and indicate no problem of multicollinearity.

\section{Methods of Analysis}

The specification of the multiple regression model used in this study is as follows:

$\mathrm{WCD}=\alpha+\beta_{1}($ CCult $)+\beta_{2}($ CClim $)+\beta_{3}($ CPract $)+e$

Where,

$\alpha=$ Constant, $\beta_{1}, \beta_{2}, \beta_{3}$, = beta coefficients and $\mathrm{e}=$ error term

$\mathrm{WCD}=$ Women career development, Ccult $=$ Corporate culture,

CClim $=$ Corporate climate, CPract $=$ Corporate Practice 


\section{Results}

\section{Descriptive analysis}

Table 1

Socio-demographic profiles of respondents

\begin{tabular}{|c|c|c|c|}
\hline Personality & & Respondent & Percentage (\%) \\
\hline \multirow{5}{*}{ Marital Status } & Unmarried & 5 & 3.5 \\
\hline & Married & 139 & 96.5 \\
\hline & Divorced & 0 & 0 \\
\hline & Widow & 0 & 0 \\
\hline & Total & 144 & 100 \\
\hline \multirow{6}{*}{ Service Year } & $\leq 5$ & 4 & 2.8 \\
\hline & $>5 \leq 10$ & 40 & 27.8 \\
\hline & $>10 \leq 15$ & 47 & 32.6 \\
\hline & $>15 \leq 20$ & 35 & 24.3 \\
\hline & Above 20 & 18 & 12.5 \\
\hline & Total & 144 & 100 \\
\hline \multirow{5}{*}{ Education } & Bachelor & 9 & 6.3 \\
\hline & Masters & 135 & 93.8 \\
\hline & M.Phil & 0 & 0 \\
\hline & $\mathrm{Ph} . \mathrm{D}$ & 0 & 0 \\
\hline & Total & 144 & 100 \\
\hline \multirow{7}{*}{ Age } & $\leq 30$ & 4 & 2.8 \\
\hline & $>30 \leq 35$ & 48 & 33.3 \\
\hline & $>35 \leq 40$ & 48 & 33.3 \\
\hline & $>40 \leq 45$ & 19 & 13.2 \\
\hline & $>45 \leq 50$ & 23 & 16.0 \\
\hline & Above 50 & 2 & 1.4 \\
\hline & Total & 144 & 100 \\
\hline \multirow{5}{*}{$\begin{array}{l}\text { Monthly stipend including basic } \\
\text { and extra }\end{array}$} & Less than 40000 & 0 & 0 \\
\hline & $40001-60000$ & 25 & 17.4 \\
\hline & $60001-80000$ & 82 & 56.9 \\
\hline & Above 80000 & 37 & 25.7 \\
\hline & Total & 144 & 100 \\
\hline
\end{tabular}

(Source: Researcher's field survey)

For this study one hundred forty- four women branch managers have been taken from twenty-five commercial banks. The highest percentage of respondents was married with 96.5 percent as compared to unmarried with 3.5 percent.

Regarding the service year in the banking sector, most of the respondents ( 32.6 percent) had working experience between $>10 \leq 15$ years, whereas 27.8 percent had between $>5 \leq 10$ years, 24.3 percent had between $>15 \leq 20$ years, 12.5 percent had above 20 years of experience and only 2.1 percent had less than or equal to 5 years of experience. Regarding the educational level of respondents, the study showed that masters with the highest percentage at 93.8 percent, whereas a bachelor with 6.3 percent.

Regarding the age group of respondents, the study showed that respondents were mostly between $>30 \leq 35$ years and $>35 \leq 40$ with 33.3 percent, $>45 \leq 50$ years with 16 percent, $>40 \leq 45$ years with 13.2 percent, $\leq 30$ years with 2.8 percent and above 50 years with 1.4 percent. Regarding monthly stipend including basic and extra, 56.9 percent of them had earned between Rs. 60001 to Rs. 80000, 25.7 percent 
of them had above Rs. 80000 and 17.4 of them had between Rs. 40001 to Rs. 60000 .

Correlation between GC scale and WCD scale of women branch manager

Table 2

Correlation between GC scale and WCD scale

\begin{tabular}{lcc}
\hline & \multicolumn{2}{c}{ Correlation coefficient } \\
\hline Scales & GC & WCD \\
GC & 1.000 & \\
WCD & $-.740^{*}$ & 1.000 \\
\hline
\end{tabular}

*. Correlation is significant at the 0.05 level (2-tailed).

Table 2 shows that there is a strong significant negative correlation between the GC scale and WCD scale score $(r=-0.740)$. It indicates that the increase in GC in organizations decrease the WCD and vice versa.

\section{Relationship between glass ceiling variables and women career development}

Table 3

Relationship between glass ceiling variables and women career development

\begin{tabular}{ll}
\hline Variables & Glass ceiling and Women career development \\
\hline & $\beta=6.053^{*}$ \\
Constant & $(36.419)$ \\
& 0.000 \\
\hline & $\beta=-0.098$ \\
Corporate culture & $(-1.086)$ \\
& 0.279 \\
\hline & $\beta=-0.737^{*}$ \\
Corporate climate & $(-6.463)$ \\
& 0.000 \\
\hline & $\beta=-0.081$ \\
Corporate practice & $(-0.813)$ \\
& 0.418 \\
\hline R square & 0.595 \\
F-statistics & $68.536^{*}$ \\
\hline
\end{tabular}

*, Coefficient is significant at 0.05 level of significance

The values in the parentheses are $\mathrm{t}$-statistics and italicized values are $\mathrm{p}$ values.

Table 3 shows the result of multiple regression analysis for showing the relationship between WCD and $\mathrm{GC}$ variables. One variablecorporate climate ( $\mathrm{p}$-value $=0.000<0.05)$ is found to be statistically significant at 0.05 level of significance. The variablecorporate climate $(\beta=-0.737)$ hasa negative relationship with GCas indicated by a negative sign of the beta coefficient. Hence the results revealed that the career of women in the banking sector can be developed by decreasing GC related to corporate climate.

In this model, the value of R-square is 0.595 which indicates that around 59.5 percent of the variation in WCD is explained by the measures of GC used as independent variables in the model. The value of F-statistics is 68.536 , which is significant at 0.05 level of significance indicating adequacy of model fit. Among the three variables, two variables (corporate culture and corporate practice) are not found statistically significant in the CD of women branch managers of commercial banks. Since only the variablecorporate 
Silver Jubilee Issue - 2019

climate is found to be significant in the model so further analysis included the relationship between WCD and various items of corporate climate. For this, one additional multiple regression was run employing WCD as the dependent variable and items of GC measures corporate climate as an independent variable. The output of the models is explained in the following sections.

\section{Relationship between women career development and corporate climate}

Table 4

Relationship between women career development and corporate climate

\begin{tabular}{|c|c|}
\hline Variables & women career development and corporate climate \\
\hline \multirow{3}{*}{ Constant } & $\beta=5.606^{*}$ \\
\hline & $(29.664)$ \\
\hline & 0.000 \\
\hline \multirow{3}{*}{$\begin{array}{l}\text { Women receive a more unfair judgment of their work } \\
\text { performance than men }\end{array}$} & $\beta=-0.074$ \\
\hline & $(-1.020)$ \\
\hline & 0.309 \\
\hline \multirow{3}{*}{$\begin{array}{l}\text { Organization perceives that women's advancement to } \\
\text { the top position is not important because they are not } \\
\text { primary income earner }\end{array}$} & $\beta=-0.106$ \\
\hline & $(-1.440)$ \\
\hline & 0.152 \\
\hline \multirow{3}{*}{$\begin{array}{l}\text { Organization's negative perceptions and stereotypes } \\
\text { about women's professional capabilities constitute } \\
\text { barriers to women's advancement to the top position }\end{array}$} & $\beta=-0.098$ \\
\hline & $(-1.346)$ \\
\hline & 0.181 \\
\hline \multirow{3}{*}{$\begin{array}{l}\text { Organization perceives that women are less } \\
\text { committed at the workplace }\end{array}$} & $\beta=-0.098$ \\
\hline & $(-1.765)$ \\
\hline & 0.080 \\
\hline \multirow{3}{*}{$\begin{array}{l}\text { Working life is characterized by negative attitudes } \\
\text { towards women }\end{array}$} & 0.013 \\
\hline & $(0.208)$ \\
\hline & 0.836 \\
\hline \multirow{3}{*}{$\begin{array}{l}\text { Women believe that their working abilities are } \\
\text { underestimated while assigning job by management } \\
\text { and superiors because they are women }\end{array}$} & $-0.410^{*}$ \\
\hline & $(-5.595)$ \\
\hline & 0.000 \\
\hline \multirow{3}{*}{$\begin{array}{l}\text { Women have to perform better than their male } \\
\text { counterpart to be promoted to the same position }\end{array}$} & 0.021 \\
\hline & $(0.289)$ \\
\hline & 0.773 \\
\hline $\mathrm{R}$ square & 0.640 \\
\hline \multirow{2}{*}{ F-statistics } & $34.512 *$ \\
\hline & 0.000 \\
\hline
\end{tabular}

*, Coefficient is significant at 0.05 level of significance

The values in the parentheses are t-statistics and italicized values are $\mathrm{p}$ values.

Table 4 shows that there is a significant difference in the CD of women branch managers for agreement factor of corporate climate "Women believe that their working abilities are underestimated while assigning job by management and superiors because they are women" at 0.05 level of significance. It can be 
inferred that the CD of women is greatly influenced by the organization's negative perception of women's capabilities. Based on the result WCD is not influenced by other items of corporate climate under GC.

\section{Existence of glass ceiling in commercial banks}

Table 5

Respondents viewpoint towards the existence of the glass ceiling in an organization

\begin{tabular}{lcc}
\hline Response & Frequency & Percentage (\%) \\
\hline To no extent & 7 & 4.9 \\
To a little extent & 94 & 65.3 \\
To a moderate extent & 30 & 20.8 \\
To a great extent & 11 & 7.6 \\
To a very great extent & 2 & 1.4 \\
Total & 144 & 100 \\
\hline
\end{tabular}

Data analysis from the survey confirmed that women in Nepalese commercial banks had to face various barriers in their career progression. 65.3 percent of respondents felt the existence of the glass ceiling to a little extent while 1.4 percent of them even felt to a great extent. Similarly, only 4.9 percent of respondents did not feel the existence of GC. Based on the result it can be assumed that GC has still existed in commercial banks in Nepal.

\section{Discussion}

This study tried to analyze the relationship between GC and CD of women branch managers in commercial banks in Nepal. The result revealed that a strong negative correlation between GC scale and WCDscale indicating that the presence of GC in commercial bank hampers $\mathrm{CD}$ of women branch managers supporting alternative hypothesis H1set for the study. This result is also supported by (Bombuwela, et al.,2013) their study showed a significant negative relationship between the GC scale and WCD scale ( $\mathrm{r}=$ -0.464). Furthermore result revealed that GC has an impact on WCD supporting the result of (Bombuwela, et al.,2013). Under corporate climate, "Women believe that their working abilities are underestimated while assigning job by management and superiors because they are women" is found to be affected by the CD of women branch managers. This result is consistent with Morrison et al.(1987) say women are now capable of moving to upper levels, at some point they are halted by an invisible barrier. It applies to women as a group who are kept from advancing higher because they are women. The majority of the respondents felt the presence of GC in their organization to a little extent and is supported by (Thao, 2014) whereas only a very few respondents said that there is an absence of GC. It indicates that there is still the existence of GC that constitutes a barrier to the career development of women.

\section{Conclusion}

Findings of the study showed that among predictors of WCD (corporate culture, corporate climate, and corporate practice) only one predictor "corporate climate" has a higher degree of a negative relationship with WCD. Among the three variables of GC, the corporate climate seemed to be effective for determining WCD. Under this variable, "Women believe that their working abilities are underestimated while assigning job by management and superiors because they are women" seemed to be effected in their CD. According to the result revealed, it can be assumed that the organization has still preoccupied mindset about negative perception towards women's capability. Gender bias can be observed from this result. Because of this reason, the organization cannot promote women to a higher position. If the organization does not assign a job for women underestimating their capability, women will not get the opportunity for learning and growth ultimately leading to the career break. The majority of the women branch managers in commercial banks 
have felt the existence of GC in their organization. So it is better to detach such stereotype based on gender from the mindset of the organization for the removal of the glass ceiling. The organization is better to create such a working environment that subordinates are working under the intelligence of a leader not under a leadership based on gender.

\section{Implications}

The results of the study have some implications for understanding the impact of GC on WCD in Nepalese commercial banks. The study emphasizes the importance of the relationship between GC and WCD of women branch managers. Results of various studies have confirmed the benefits of removing the $\mathrm{GC}$ in the organization and to attract talent to make the organization more representative ethical, productive, innovative and financially successful (Northouse, 2012).Investigation of the multiple layers of GC that female executives are facing can help organizations to engage the right people for the right jobs and make full use of their unique qualities to support organizational performance (Hartel and Fujimoto, 2010). So it has been very essential to abolish the GC in the organization for achieving competitiveness. This study allows the policymaker to understand the different dimensions of GC. The issues related to GC identified in this study can help policymakers improve the corporate climate by removing stereotyping based on gender in Nepalese commercial banks. This study has some limitations, which may provide opportunities for a future researcher. For this all-female employees working at different levels can be drawn as a sample for the study.Moreover, it is proposed that future research should be conducted in other sectors as well to understand the situation of the glass ceiling.

\section{Acknowledgments}

This research article is based on the M.Phil thesis awarded under M.Phil Fellowship by University Grants Commission, Nepal (UGC). So I would like to thank UGC for this support.

\section{References}

Alvesson, M., and Billing, Y. D. (2010). Understanding Gender and Organizations. Journal of Industrial Relations, 52(4), 526-528. http://dx.doi.org/10.1177/00221856100520040703

Bergman, B. and Hallberg, L. (2002). Women in a male-dominated industry: factor analysis of a women workplace culture questionnaire based on a grounded theory model, Sex Roles. A Journal of Research, 12, 311-336.

Bombuwela, P. M., Alwis, D., and Chamaru, A. (2013). Effects of glass ceiling on women career development in private sector organizations- case of Sri Lanka. Journal of Competitiveness, 5(2), 3-19.

Buttigieg, D., and Walsh, J. (2000). How do women fare in internal labor markets? Evidence from the Australian and British banking industries. The Journal of Industrial Relations, 42(3), 351-365.

Catalyst (2018). Women CEOs of the S and P 500 companies. New work. Retrieved from: http://www. catalyst.org/knowledge/women-ceos-sp-500 [2018, April 8].

Central Bureau of Statistics (2009). Report of the Nepal Labour Force Survey 2008. Kathmandu, Nepal: Author.

Cooper, J. (2001). Women middle managers' perception of the glass ceiling. Women in Management Review, $16(1), 30-41$.

Dimovski, V., Skerlarvaj, M., and Mandy Kim Man, M. (2010).Is there a 'Glass Ceiling' for female managers in Singapore organizations? Management, 5(4), 307-329.

Greenhaus, J. H., Parasuraman, S., and Wormley, W. M. (1990). Effects of race on organizational experiences, job performance evaluations, and career outcomes. Academy of Management Journal, 33, 64-86.

Hartel, C. E. J., and Fujimoto, Y. (2010). Human resource management (2nd ed.). French Forest, Australia: Pearson Australia.

Jackson, J. (2001). Women middle managers' perception of the glass ceiling. Women in Management 
Review, 16 (1), 30-41.

Jamali, D., Safieddine, A., and Daouk, M. (2006). The glass ceiling some positive trends from the Lebanese banking sector. Women in Management Review, 21(8), 625-642.

Judge, T. A., Cable, D. M., Boudreau, J. W., and Bretz, R. D. (1995). An empirical investigation of the predictors of executive career success. Personnel Psychology, 48(3), 485-519.

Knuston, B., and Schmidgall, R. (1999). Dimensions of the glass ceiling in the hospitality industry. Cornell Hotel and Restaurant Administration Quarterly, 40(6), 64-75.

Mavin, S. (2000). Approaches to careers in management: Why UK organizations should consider gender. Career Development International, 5(1), 13-20.

Meyerson, D. and Fletcher, J. (2000). A modest manifesto for shattering the glass ceiling. Harvard Business Review, 78(1), 127-140.

Morrison, A. M., White, R. P., Velsor, E., and the Center for Creative Leadership (1987). Breaking the GC: Can women reach the top of America's largest corporations? Reading, MA: Addison Wesley.

Mott, V. (1998). Women's career development in mid-life and beyond. New Direction for Adult and Continuing Education. 80, 25-33.

Naseer, M., Shabbir, M. and Batool, Z. (2017). An exploratory study of the factors responsible for a glass ceiling in the Public Sector of Punjab, Pakistan. Journal of Applied Environmental and Biological Sciences, 7(11), 60-65.

Northouse, P. G. (2012). Introduction to leadership: Concepts and practice (2nd ed.). Thousand Oaks, CA: SAGE Publications, Inc.

Nunnaly, J. C., and Bernstein, I. H. (1994). The assessment of reliability. Psychometric Theory, 3, 248-292.

Ragins, B. R., Townsend, B. and Mattis, M. (1998). the gender gap in the executive suite: CEOs and female executives report on breaking the glass ceiling. Academy of Management Executive, 12(1), 28-42.

Robbins, S. and Coulter, M. (2003). Management. Prentice-Hall, Upper Saddle River, NJ.

Thao, T. T. (2014). Identifying the existence of the glass ceiling and examining the impact on the participation of female executives in the Vietnamese banking sector (Masers' thesis, Unitec Institute of Technology, New Zealand). Retrieved from https://uunz.ac.nz/media/uploads/2018/07/03-1-16 
